\title{
Modeling the educational process on the example of training volleyball players
}

\section{Modelar el proceso educativo a partir del ejemplo de la formación de jugadores de voleibol}

\author{
Maxim M. Kutepov \\ kmm-asb@mail.ru \\ https://orcid.org/0000-0002-5397-6168 \\ Minin Nizhny Novgorod State Pedagogical University, Nizhny Novgorod, Russia. \\ Vasiliy A. Razorenov \\ rvasek82@mail.ru \\ https://orcid.org/0000-0001-8455-3785 \\ Minin Nizhny Novgorod State Pedagogical University, Nizhny Novgorod, Russia. \\ Natalya E. Zhitnikova \\ g-nat73@mail.ru \\ https://orcid.org/0000-0001-8547-3699 \\ Minin Nizhny Novgorod State Pedagogical University, Nizhny Novgorod, Russia. \\ Elena V. Lukina \\ lukina.ieliena@mail.ru \\ https://orcid.org/0000-0003-1437-3337 \\ Minin Nizhny Novgorod State Pedagogical University, Nizhny Novgorod, Russia. \\ Ivan A. Sedov \\ ivansedof@yandex.ru \\ https://orcid.org/0000-0003-3904-7562 \\ Minin Nizhny Novgorod State Pedagogical University, Nizhny Novgorod, Russia.
}

\section{Abstract}

Recibido: $2 / 08 / 21$

Aceptado: 23/10/21

The purpose of the article is to analyze the experience of modeling the educational and training process for training volleyball players. Methodology: the research is carried out on the example of volleyball players' educational-training process formation. The article reveals the process of speed-strength readiness as an indicator characterizing the success of the performance of game teams. The research includes revealing the influence of students' physical abilities on the effectiveness of competitive activity: speedstrength, agility, endurance. Results: carrying out tests by Uchelli and Bosco allow determining the effectiveness of the model of the educational and training process implemented in training volleyball players. 
Key Words: educational and training process, model, sports training, professional competence, physical culture.

\section{Resumen}

El propósito del artículo es analizar la experiencia de modelar el proceso educativo y formativo para la formación de jugadores de voleibol. Metodología: la investigación se realiza sobre el ejemplo del proceso de formación educativo-formativo de los jugadores de voleibol. El artículo revela el proceso de preparación velocidad-fuerza como un indicador que caracteriza el éxito del desempeño de los equipos de juego. La investigación incluye revelar la influencia de las habilidades físicas de los estudiantes en la efectividad de la actividad competitiva: velocidad-fuerza, agilidad, resistencia. Resultados: la realización de pruebas de Uchelli y Bosco permiten determinar la efectividad del modelo del proceso educativo y formativo implementado en la formación de jugadores de voleibol.

Palabras clave: proceso educativo y formativo, modelo, formación deportiva, competencia profesional, cultura física.

\section{Introduction}

The organization of the educational and training process for future specialists in physical culture and sports is of particular importance since it is a means of forming professional competence, which, in turn, is one of the main goals of modern professional education. Modeling the educational and training process contributes to an increase in the effectiveness of sports training, which is primarily associated with a high level of motivation of students and their desire to improve sports achievements (Bogdanova \& Fedorova, 2020).

The second group of models includes models of large structural formations, such as stages of preparation, their periods; models of training stages, cycles; models of training sessions; exercise models and their complexes (Shashlo et al., 2018).

With an increase in the duration of the competitive period, additional requirements appear for the organization of the educational and training process and the process of physical training of students (Yarygin et al., 2019). Among these requirements is the preservation of optimal physical shape (Ponachugin \& Lapygin et al., 2019). Thesimulated educational and training process is aimed at solving the problems of the formation of professional competencies associated with an increase in the level of manifestation of motor abilities, the development and strengthening of functional systems of the body, prevention and reduction of injuries in volleyball players (Nagovitsyn et al., 2020).

Modeling allows developing the technical training of specialists in physical culture and sports. Students will be able to use the available arsenal of technical and tactical actions 
and apply them in specific situations by the characteristics of the enemy's tactics (Demidov \& Tretyakov, 2016a). Team tactics imply the solution of a set task by each player of the team, therefore the result depends on each player, their interaction in the game (Ivanova \& Korostelev, 2019).

The educational and training process is based on the ideas of the development of physical, technical training, team tactics (Demidov \& Tretyakov, 2016b). Following this, the modeling of the educational and training process includes three stages: the formation of physical readiness, technical readiness, the development of the group and team tactics (Smirnova et al., 2020). Methods for diagnosing strength abilities are divided into two groups: instruments and technical devices; exercise tests (Solomchenko, 2015).

Modeling of the educational and training process is based on the principles of maximization and in-depth specialized specialization of training loads.

The structure and content of training volleyball players are based on the construction of competitive physical activity since volleyball is a team sport and the game takes place in constantly changing conditions with a lack of time.

\section{Theoretical framework}

Different types of models are involved in sports training, which can be combined into two groups (Aniskin et al., 2020). The first includes models of the structure of competitive activity and its characteristics, which are important for achieving the set goals (Vaganova et al., 2020).

The same group includes models that characterize the main aspects of a student's readiness, provide sports and competitive activities (Bulaeva, et al., 2018). The modeling takes into account two directly interconnected links: the age-related dynamics of the development of physical qualities and the degree of utilization of physical capabilities (Dobudko et al., 2019).

In the process of modeling, it is important to achieve the optimal balance of the level of development of physical qualities (Vaganova et al., 2019).

The educational and training process includes many aspects. Special attention is paid to technical and team tactics. For the correct construction of the educational process, it is necessary to adhere to the principle "from simple to complex".

The basic component of the technique of playing volleyball is standing and movement. These are the most productive elements in the movement process. The starting positions, in this case, depending on various factors. In the second gear, a high stance (Tsarapkina et al., 2021). If the ball is received from the serve, then the middle stance is used, with the power serve, the low stance is used. Movement includes running, walking, various types of movements (for example, side steps, backward steps). 
When training volleyball players, it is important to teach them to combine movement methods for the best results.

Team tactical actions include: the second transfer of the front row player, the second transfer of the player leaving the backcourts into one of the attacking zones.

The technical training of basketball players is one of the most important components. The main task of the players is to imitate the game behavior model as accurately as possible (Tezer et al., 2019).

For an effective game, the physical development of athletes, timely diagnosis of errors and the appropriate selection of means for correcting movements are important.

The requirements for those engaged in the training process should gradually increase to maintain a high level of quality in the performance of the set game tasks.

\section{Methodology}

The study involved 66 students. Based on the results of preliminary tests, the participants were divided into groups. The research is aimed at checking the effectiveness of the proposed model of the educational and training process.

The table shows the age of the participants.

Table 1.

Characteristics of study participants.

\begin{tabular}{lllll}
\hline Group & $\begin{array}{l}\text { Number } \\
\text { of } \\
\text { persons }\end{array}$ & \multicolumn{1}{c}{ Age } & Height (cm) & Weight \\
\hline KG -1 & 22 & 19 to 22 & $185 \pm 5$ & 83 to 85 \\
\hline KG -2 & 22 & 20 to 23 & $183 \pm 3$ & 82 to 86 \\
\hline EG & 22 & 20 to 24 & $187 \pm 4$ & 84 to 85 \\
\hline
\end{tabular}

Control groups are divided into junior and senior. Their training was carried out before the introduction of the model of the educational and training process. The results of the experimental group were recorded after applying the model.

CG - control group, EG - experimental group. In the process of modeling, the degree of detail of the models is determined, the duration of the model development time is set. The object of control is the student's organism. The developed model includes a three-stage training of volleyball players in the preparatory period. The content of training programs determines the volume of training loads. The research includes tests to identify the level 
of influence of various physical abilities on the results of the competitive activity of volleyball players.

For the study, the previously collected results of volleyball players for 2018-2019 were used. On their basis, exercises and tests (Uchelli, Bosco test) were proposed and introduced into the model of the educational and training process. To determine the height of the jump, the difference between the best result and the mark obtained in the hand up position while standing on toes was calculated. The result was recorded in centimeters. The determination of the mechanical power of the jumps was performed using the Bosco test. The selected fifteen-second interval allows a high confidence factor to be demonstrated. The performed jumps were recorded visually, then the results were recorded by two testers for 15 seconds. The result obtained in watts was converted to the student's weight in kilograms.

The implementation of the training programs was carried out in groups distributed according to the initial strength training.

\section{Results and discussion}

The proposed model includes a target component, which is aimed at improving the training process, taking into account the new requirements for the training of volleyball players. The content-process component includes unidirectional training impact, block periodization, modern methods and means of training the most significant abilities: speedpower, speed, endurance, agility. The component includes the organization and management of the training process on the part of the teacher, recording the results of students and correcting training, conducting training sessions using exercises that develop students ' physical abilities. The performance component reflects the improvement of volleyball players ' results due to the improvement of the training process (Vaganova et al., 2019).

The training session includes the introductory part, the main part and the final part. The introductory part involves a warm-up session (Kidina, 2020). The main part takes into account the ratio of the time of performing exercises, the intensity of loads, and the rest time. The final part includes a static stretch. Conducting classes in the established mode allows students to adapt to the training process (Misakov et al., 2019). The individual state of the student's body is taken into account, and the training load is distributed evenly. During the lesson, the load is carried out in the same direction and the same methods and means are used (Kiseleva et al., 2019).

The study includes testing the influence of physical abilities on the effectiveness of competitive activities. Some of the most significant abilities are speed-power, speed, endurance, agility. Students show speed-power abilities when attacking blows, blocking or passing the ball in a jump (Kharytonov et al., 2019). Speed abilities and endurance allow you to effectively perform all the game actions throughout the game. Agility allows the volleyball player to control his body while performing the jump. Game endurance is a 
combination of physical qualities and special endurance. Modeling of the training process is carried out based on taking into account the development of the necessary physical abilities and includes appropriate exercises (Pichugina \& Bondarchuk, 2019). The developed model involves alternating exercises in a certain sequence. The training mode is set according to the content of the load components (Pinkovetskaia et al., 2020).

The study uses the Uccelli test, which allows you to determine the highest possible jump mark. Since jumping is an integral part of the game, the Uccelli test will allow you to improve them and improve your performance. Students performed three jumps; the best result was taken into account. To determine the height of the jump, the difference between the best result and the mark obtained in the hand-up position standing on the toes was calculated. The result was recorded in centimeters. The Bosco test is performed to determine the mechanical power of performing jumps. The actual conditions for performing jumps in competitive activities reflect the fifteen-second interval, so it was chosen for the study.

To test strength abilities, exercise machines and dynamometers are used as the most common tools (hand and wall). Exercises-tests (long jumps, pull-ups, leg press in the simulator, barbell press, wall dynamometry, height of setting blocks, and others).

A fragment of the training content is presented in the table.

Table 2.

Content of training of students.

\begin{tabular}{ccc}
\hline An exercise & Amount & Approaches \\
\hline $\begin{array}{c}\text { Reduction of hands in the } \\
\text { simulator }\end{array}$ & 40 minutes & 5 \\
\hline Barbell bench press & 7 repetitions & 6 \\
\hline Leg press in the simulator & 14 repetitions & 4 \\
\hline Deadlift & 13 repetitions & 5 \\
\hline
\end{tabular}

With the development of maximum strength without increasing muscle mass, the amount of weight varies in the range from $50-60$ to $90-100 \%$ of the maximum strength level. The acceptable temp is $1.5-2.5$ seconds for each repetition.

The weight of the weights is shown in Table 3. 
Table 3.

Weight weights during exercise.

\begin{tabular}{cccc}
\hline An exercise & Weight & Number of approaches & $\begin{array}{c}\text { The number of } \\
\text { repetitions in the } \\
\text { approach }\end{array}$ \\
\hline $\begin{array}{c}\text { With } \\
\text { dumbbells }\end{array}$ & Up to $5 \mathrm{~kg}$ & $7-8$ & $10-12$ times \\
\hline With belt & $\begin{array}{c}\text { Up to } 10 \\
\mathrm{~kg}\end{array}$ & $7-8$ & $10-12$ times \\
\hline With kettlebell & $\begin{array}{c}\text { Up to } 16 \\
\mathrm{~kg}\end{array}$ & 3 & $10-12$ times \\
\hline Barbell & & $\%$ of own weight & \\
\hline
\end{tabular}

When training the strength of volleyball players, the following methods are used: repeated efforts, conjugate, circular training.

At the same time, the following methodological provisions are observed: observance of the continuity of tasks, means and methods at all stages of training; scientifically grounded distribution of the volume and intensity of the load, taking into account the individual characteristics of the student; gradual use of exercises.

Figure 1 shows the results of the control and experimental groups on the Uchelli test.

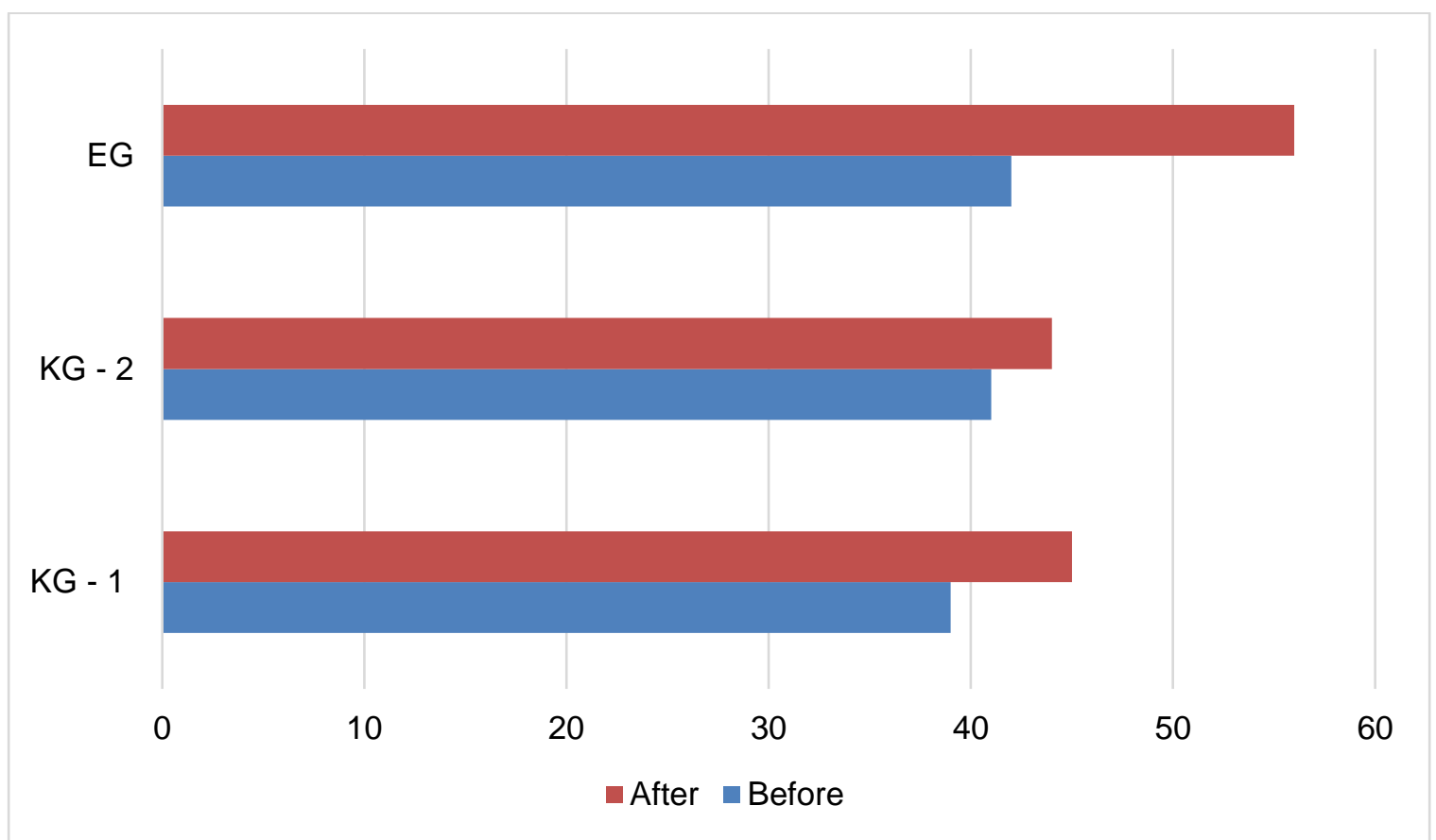

Figure 1. Results of the Uchelli test before and after model implementation. 
The increase in positive results in the experimental group exceeded the results of the control groups, which indicates the effectiveness of the used model. Figure 2 shows the results of the Bosco test.

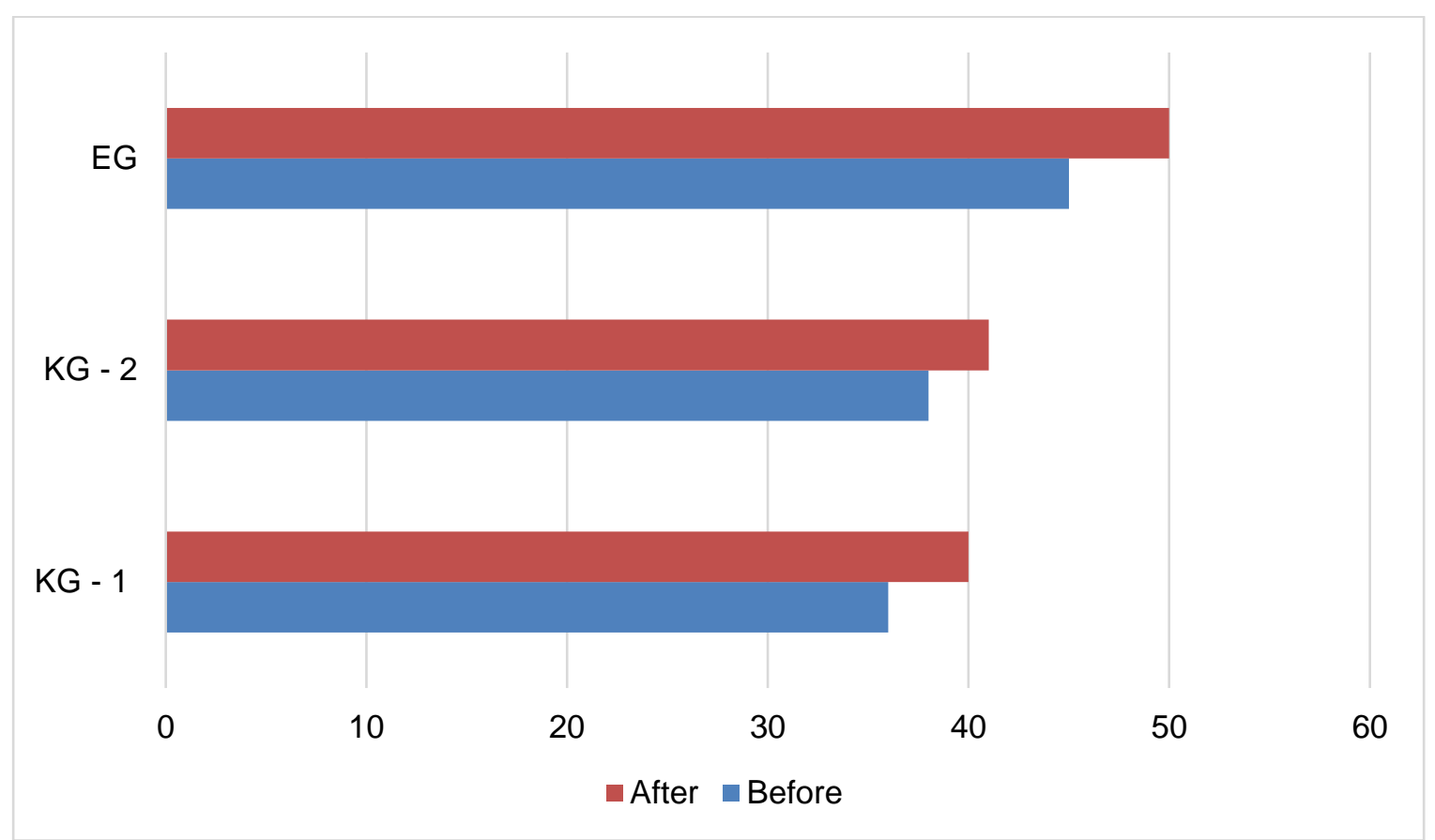

Figure 2. Results of the Bosco test before and after model implementation.

Note that the model was implemented only in the experimental group. The improvement in the results of the control groups is insignificant and is not associated with the introduction of changes in the training process. After the implementation of the model, the students of the experimental group show higher results in performing the Bosco test compared to the control groups.

Figure 3 shows the upward jump measurement. 


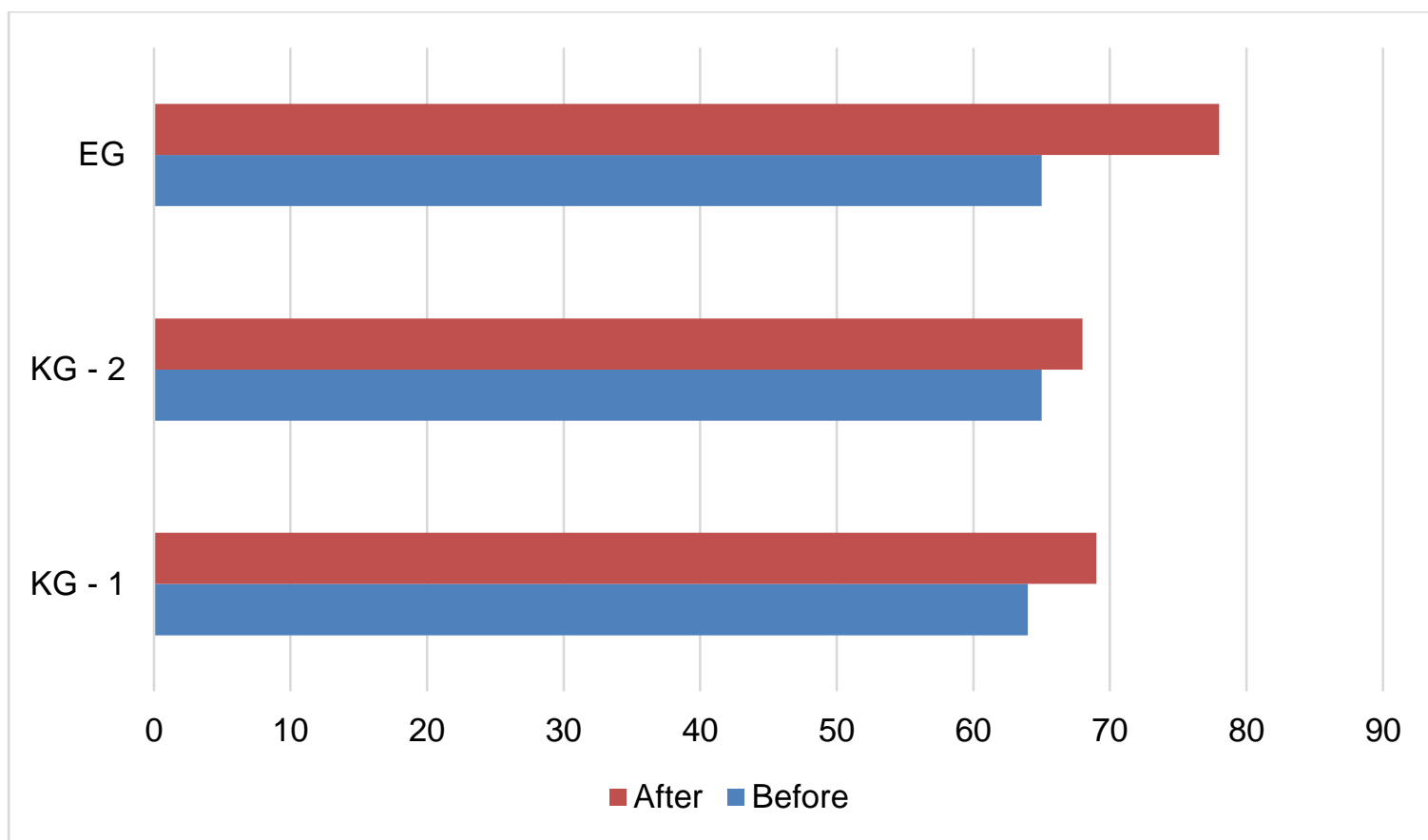

Figure 3. The results of measuring the jump.

Students' high jumps after the implementation of the model became much better. The model of the educational-training process made it possible to evenly distribute the load and gradually increase it. Due to this, students better adapt to the gameplay and increase their performance.

It should be noted that the game actions of students became clearer, according to the observations of teachers, the effectiveness of tactical and speed-strength readiness increased.

\section{Conclusions}

The paper presents a model of the educational and training process of volleyball players, which includes three components: target, content-procedural, effective. The model makes it possible to make the process of training volleyball players more systematic and progressive, taking into account the individual characteristics of students and the development of basic physical capabilities.

The developed model of the educational-training process contributed to more effective control of the complex mechanism of training volleyball players, allowed to make appropriate adjustments to the content of educational-training sessions. The study allowed to establish an increase in test results.

The results in the experimental group, where the model of the educational-training process was introduced, are significantly higher than in the control groups. Minor 
improvements in results are not stable and are not associated with changes in the educational and training process. The implementation of the model made it possible to improve the performance of the Uchelli and Bosco tests, improve the results of the jump height.

\section{Bibliographicreferences}

Aniskin, V. N., Korostelev, A. A., Lvovna, B. A., Kurochkin, A. V., \& Sobakina, T. G. (2020). Teaching potential of integrated learning technologies Smart, Stem and Steam. Revista De La Universidad Del Zulia, 11(29), 328-336.

Arbeláez-Campillo, D., Tatsiy, V., Rojas-Bahamón, M., \& Danilyan, O. (2020). Contributions of critical thinking as a form of participation and political deliberation. Amazonia Investiga, 9(27), 5-12. https://doi.org/10.34069/Al/2020.27.03.1

Bulaeva, M. N., Vaganova, O. I., Koldina, M. I., Lapshova, A. V., Khizhnyi, A.V. (2018). Preparation of Bachelors of Professional Training Using MOODLE. Advances in intelligent systems and computing, 622, pp. 406-411.

Bogdanova, A.N., \& Fedorova, G.A. (2020). The use of interactive surveys in lectures on the discipline "information and communication technologies and media information literacy". Bulletin of the Siberian Institute of Business and Information Technologies, (1 (33)), 4-9.

Dobudko, T.V., Korostelev A.A., Gorbatov, S.V., Kurochkin, A.V., \& Akhmetov, L.G. (2019). The organization of the university educational process in terms of digitalization of education. Humanities and Social Sciences Reviews. 7(4), pp. 1148-1154.

Demidov, A.A. Tretyakov, A.L. (2016a). A network model of centers for ethical and legal education and civil-patriotic education and media education centers based on school libraries: the need to create, opportunities and real prospects, Media Education (Mediaobrazovanie), 3, pp. 16-22.

Demidov, A.A., \& Tretyakov, A.L. (2016b) Centers for ethical and legal information and media education based on the school library - an innovation in the implementation of the Federal State Educational Standard and infrastructure for the development of information and legal culture of children and youth. Media Education (Mediaobrazovanie), 2, pp. 21-33.

Ivanova, N., \& Korostelev, A. (2019). The impact of competitive approach on students' motivation in sport. Amazonia Investiga, 8(18), 483-490. Retrieved from https://amazoniainvestiga.info/index.php/amazonia/article/view/362

Kidina I. M. (2020). Management of the pedagogical collective in the conditions of implementing distance learning. Baltic Humanitarian Journal. (Baltic Humanitarian Journal), Vol. 9 No 4 (33), pp. 93-96.

Kharytonov, E., Kharytonova, O., Tolmachevska, Y., Fasii, B., \& Tkalych, M. (2019). Information Security and Means of Its Legal Support. Amazonia Investiga, 8(19), 255-265. Retrieved from https://amazoniainvestiga.info/index.php/amazonia/article/view/227

Kiseleva, O., Lebedev, A., Pinkovetskaia, I., Rojas-Bahamón, M., \& Arbeláez Campillo, D. (2019). Specialization and concentration of small and medium enterprises employees: Russian data. Amazonia Investiga, 8(20), 6-15. Retrieved from https://amazoniainvestiga.info/index.php/amazonia/article/view/59 
Misakov, V., Tsurova, L., Yandarbayeva, L., Tkhamadokova, I., \& Gapurovna, G. (2019). Certification of A Regional Economic Complex as A Highly Effective Tool for analysis and diagnostics of its development. Amazonia Investiga, 8(20), 451-458. Retrieved from https://amazoniainvestiga.info/index.php/amazonia/article/view/174

Nagovitsyn, R. S., Vaganova, O. I., Kutepov, M. L. N., Kosenovich, O. V., Moeseev, Yu. V., Vorotova, M. S., \& Osipov, A. Y. (2020). Interactive Technologies in Developing Student's Motivation in Physical Education and Sport. International Journal of Applied Exercise Physiology, 9(6), 78-85.

Pichugina, G.A., \& Bondarchuk, A.I. (2019). Structure of the training case in the organization of the educational process. Humanitarian Balkan research, 2(4), pp. 5-7.

Pinkovetskaia, I., Berezina, N., \& Sverdlikova, E. (2020). The main reasons for the exit of entrepreneurs from business. Amazonia Investiga, 9(26), 68-73. https://doi.org/10.34069/Al/2020.26.02.7

Ponachugin, A.V, \& Lapygin, Yu.N. 2019. "Digital Educational Resources of the University: Design, Analysis and Expertise". In: Vestnik Mininskogo universiteta (Vestnik of Minin University), Vol. 7 (2), 5. (in Russ)

Shashlo, N., Petruk, G., \& Korostelev, A. (2018). Determinants of integration interaction among the subjects of the entrepreneurial innovation ecosystem of macro region. Amazonia Investiga, 7(13), 351-363. Retrieved from https://amazoniainvestiga.info/index.php/amazonia/article/view/569

Solomchenko, M.A. (2015). Modeling the sports-training process: lecture notes for higher professional education. Oryol: FGBOU VPO "State University - UNPK ", 186 p.

Shcerbakova E.V., Shcerbakova T. N. (2019). Experience of Use of Remote Computer Technologies at The Organization of Independent Work of Students in The Conditions of a Mark and rating system. Baltic Humanitarian Journal. (Baltic Humanitarian Journal), Vol. 8, No 4 (29), pp. 192-195.

Smirnova, Z.V., Vezetiu, E.V., Vaganova, O.I., Pluzhnikova, E.A., Akimova, I.V. (2020). Automated knowledge management through e-testing. International Journal of Advanced Trends in Computer Science and Engineering, 9(3), pp. 3256-3260.

Tsarapkina, J. M., Plahina, L. N., Konoplyuk, N. V., Vaganova, O. I., \& Lapshova, A. V. (2021). The formation of bachelors' digital competencies at the university. Propositos $y$ representaciones, 9, № SI, Article number e811.

Tezer, M., Yildiz, E.P., Masalimova, A.R., Fatkhutdinova, A.M., Zheltukhina, M.R., \& Khairullina, E.R. (2019). Trends of augmented reality applications and research throughout the world: meta-analysis of theses, articles and papers between 2001-2019 years. International Journal of Emerging Technologies in Learning. T. 14. № 22, pp. 154-174.

Vaganova, O.I., Korostelev, A.A., Smirnova, Z.V., Abramova, N.S., \& Dolmatov, S.N. (2019). Improving teachers' professionalism through the development of creativity. International Journal of Innovative Technology and Exploring Engineering, 8(8), pp. 630-634.

Vaganova, O. I., Petrozitskaya, I. A., Snatovich, A. B., Odarich, I. N., \& Kirillova, I. K. (2020). Heuristic technologies of training in professional education. Amazonialnvestiga, 9(27), 509-517. https://doi.org/10.34069/Al/2020.27.03.55

Yarygin, O.N., Korostelev, A.A., Akhmetov, L.G., \& Maseleno, A. (2019). Modeling of competence as a tool of goal setting for education in modern society. International Journal of Recent Technology and Engineering, 7(6), pp. 72-77. 